\title{
An In Vitro Study to Evaluate the Accuracy of Different Impression Techniques of Implant Supported Prosthesis
}

\author{
Mahmoud M. El-Najjar ${ }^{(1)}$, Mohammed H. Abdel-Aziz ${ }^{(2)}$, Ahmed MY. El-Kouedi (2) ${ }^{\text {and Tamer A. Hamza }}{ }^{(3)}$
}

Codex : $54 / 1810$

azhardentj@azhar.edu.eg

http://adjg.journals.ekb.eg

\section{KEYWORDS}

Implant, Impression technique, Impression material, Open tray,

Closed tray, Splinting.

\begin{abstract}
Purpose: This study was designed to evaluate the dimensional accuracy of different impression techniques of implant-supported fixed dental prosthesis. Materials and Methods: Thirty impressions were made upon a specialized stainless-steel mold containing two parallel implant analogues. The impressions were divided into three groups according to implant impression technique used ten each; group (I) closed tray technique (C), group (II) open tray technique (O) and group (III) splinted open tray technique (OS). After taking impressions, they were poured with type IV dental stone and left for one day before analysis with a stereo microscope. Results: Regarding impression accuracy, there was no statistically significant difference between open tray and splinted open tray technique within the master mold while there was statistically significant difference between closed tray technique within the master mold. There was no statistically significant difference between open tray and splinted open tray technique while there was statistically significant difference between closed tray technique within the other two techniques. Conclusion: Closed tray technique showed more deviation in comparison to the master mold and the other two techniques that affect the final accuracy of multiple implant impression while no significant difference with the open tray technique of both types.
\end{abstract}

\section{INTRODUCTION}

Dental implants are approved to be the first choice for replacing missing teeth either partial replacement or with completely edentulous patients ${ }^{(1)}$ In an attempt for success and longevity of dental implants, passive adaptation of the supported prosthesis should be achieved when looking for biomechanical consideration as passivity is considered the first requirement for assurance of proper osseointegration ${ }^{(2,3)}$

- A paper extracted from master thesis entitled “An In Vitro Study to Evaluate the Accuracy of Different Impression Techniques of Implant Supported Prosthesis"

1. Assistant lecturer, Crown and Bridge department, Faculty of Dental Medicine for Boys, Al-Azhar University.

2. Associate professor, Crown and Bridge department, Faculty of Dental Medicine for Boys, Al-Azhar University.

3. Professor, Crown and Bridge department, Faculty of Dental Medicine for Boys, Al-Azhar University. 
On the controversy, superstructure misfit may be the reason for unfavorable problems. These problems may be manifested as mechanical or biological complications there by complications may vary from fracture within any of implant components till failure of osseointegration so misfit should be minimized as possible ${ }^{(4)}$.

According to bone quality and implant material, some degree of misfit may be tolerated without any noticeable biomechanical complications but although passive adaptation is required for survival of implant on the long term ${ }^{(5,6)}$. Many causative factors may affect accuracy of the superstructure as implant number, position, angulation, impression material and technique, and arch flexure. Different impression techniques are supposed for obtaining accurate casts ${ }^{(7,8)}$

Till now, passivity has no actual definition but implant superstructure may be considered passive if there are no any strains or static loads generated within the implant or the surrounding bone ${ }^{(9)}$. There is no complete passivity but the accepted superstructure can be described with a level of fit not generating any problems ${ }^{(10,11)}$. Mechanical tolerance is described as difference within rest positions between implant components when screwed in place. This mechanical tolerance is accepted within the range of 22-100 $\mu$. Ability of bone around dental implant to withstand forces distributed within implant-bone system without complications is defined as biological tolerance and accepted within the range of $91-111 \mu^{(12,13)}$

Closed tray technique is designed to transfer the soft tissue profile as well as the implant position. Transfer copings remains attached to the implants when the closed-tray impression is removed from the mouth. The transfer copings with this technique are parallel sided or slightly tapered for ease of removal of impression. The transfer is then retrieved from the implant, screwed to the corresponding implant analogue, and placed into its corresponding impression hole. To fabricate a working cast containing a replica of the implant in the patient's mouth, the impression is poured in dental stone ${ }^{(14,15)}$.

Local anesthesia and custom trays are not required. Additionally when there is limited mouth opening, they can be used as there may not be sufficient space for access to the screws retaining pick up type impression. Patients with gag reflex when the impression has to be removed quickly (15). Lack of predictability with the possibility of coping dislodgement during impression making. Additionally, abutments have to be fitted onto the copings and errors maybe introduced at this stage. Further soft tissue anatomy transfer is not very accurate and the size and shape of the abutment cannot be modified. Sometimes it is very difficult to remove the impressions from the mouth of the patient ${ }^{(16,17)}$.

Open tray technique is designed to transfer the soft tissue profile as well as the implant position. This transfer procedure requires a custom tray or modified stock tray with screw access holes in the areas occlusal to the implants. The transfer coping is screwed onto the implant body and sticks out of the impression. The central transfer screw must be removed before the impression can be released from the mouth. The implant analogue is connected to the transfer coping embedded within the impression, the impression is poured in dental stone to fabricate a working cast containing a replica of the implant in the patient's mouth ${ }^{(18,19)}$

This technique allows direct access to the screws that hold the transfer copings correctly positioned against each implant. The principal advantage of this technique is that the transfer coping remains in the impression and the inaccuracies of transferring are avoided. When multiple implants are present and there is a non-parallel configuration this technique is ideal as one the impression is easily retrievable and secondly there is minimum distortion of impression material ${ }^{(20)}$. Impression of prepared teeth 
must not only be dimensionally accurate but also must reproduce the surface details of prepared teeth to help fulfill fitness and success of cast restoration. Surface detail reproduction of elastic impression materials such as PVS impression materials has been evaluated ${ }^{(21)}$.

The appropriate selection of impression material brings the accuracy of the cast. The choice of material varies according to the complexity of work, impression technique, tray, implant system and prosthetic components to be used. Elastomeric impression materials are the logical choice. The most widely used are polyether and addition silicones. Both are hydrophilic, have no byproducts, excellent elastic recovery and stable ${ }^{(22-24)}$.

Splinting of implant transfer coping plays an important role for minimizing inaccuracies during clinical procedures and lab work. Various techniques of splinting and materials are used. Splinting materials as auto polymerizing acrylic resin (AAR), light cured acrylic resin (LCAR), dental floss and solid pins. Splinting effect and effect of different splinting materials isn't clear till now so the decision of which technique should be used and suitable material for splinting is a subject for many studies. Due to compositional stability of solid material, they are preferred for use to overcome the complications of other splinting materials as polymerization shrinkage of acrylic resin. There is a lack of evidence about which is the better technique and the effect of different splinting materials ${ }^{(25)}$.

The hypothesis of this study was that impression technique of implant-supported prosthesis affects the accuracy of the final impression.

\section{MATERIALS AND METHODS}

Stainless steel mold was specially designed for this study contain two implant analogues (Nucle OSS T4 analogue, $3.4 \mathrm{~mm}$ diameter $x 13 \mathrm{~mm}$ length) that held parallel to each other using the fixture adaptor on the vertical rod of dental survior and apart by $11.27 \mathrm{~mm}$ and $2 \mathrm{~mm}$ was exposed through the mold. Analogues were secured using (Total cem, Itena) resin cement (Figure 1).

Two implant level Ni-Ti coping with short screw 6mm length (Nucle OSS T4 coping) were used with closed tray technique while two others with long screw $9 \mathrm{~mm}$ length were used with open tray technique.

Two stainless steel perforated trays were specially lathe cut for making all impressions. Closed tray was made for transfer coping technique and open tray for pick up techniques of both types splinted and no splinted.

The closed tray was fabricated to have a space between the upper surface of the small mold and upper side of the tray of $5 \mathrm{~mm}$ for the length of the transfer coping and to allow of adequate thickness of impression material. Four arms were made at each corner of the tray corresponding to the four holes within the corners of the base of the mold.

The open tray was fabricated as the same as the closed tray in addition to two holes were made within the upper surface of the tray corresponding to the screw of each long transfer coping to be exposed through the tray. Another four arms were made within each corner of the upper surfaces for making a removable cover for the tray for load application during impression procedures to allow for uniform distribution of the applied load (Figure 2).

Load applicator device consists a rectangular Teflon base that connected to a curved arm containing a metallic ring within its end through which a $4 \mathrm{~kg}$ main metallic bar moves freely in a vertical direction used as supporting pressure for implant analogues cementation.

Additional bar, 500 gm, was made than can be screwed to the main bar through a large hole within the upper surface of the main bar. Two auxiliary loads, $1 \mathrm{~kg}$ per each can be added to the main bar through holding to the additional bar. The whole 


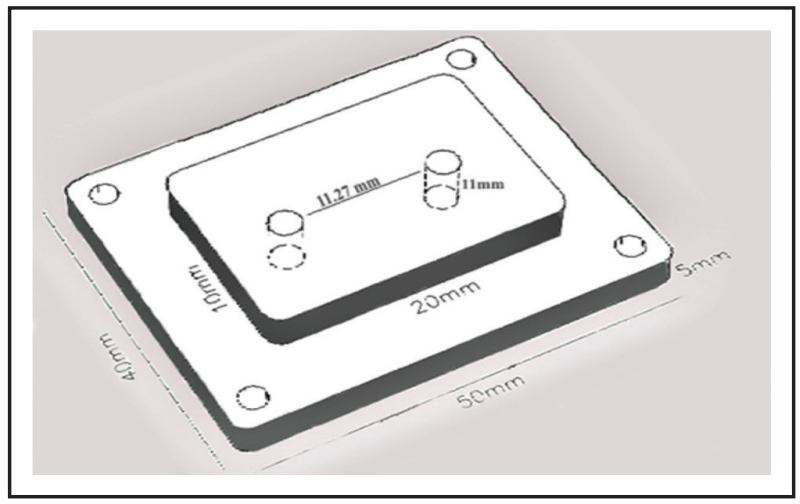

Fig. (1): Diagrammatic measurements of the mold

device, the two bars and auxiliary loads, equals 6.5 $\mathrm{kg}$ which corresponds finger pressure which used for seating the impression while for supporting the impression till impression material set, the man bar only used ${ }^{(24,25)}$ (Figure 3).

Thirty poly vinyl impressions were made upon the mold using the specialized trays. Three groups of 10 specimens each according to impression technique used. In the first group, transfer coping with short screw and closed tray were used $(\boldsymbol{C}$ group); in the second group transfer coping with long screw and open tray were used (O group); in the third group transfer coping with long screw were joined with metal splint and open tray were used (OS group).

For the splinted group solid bar was made using lathe cut to fit between the 2 impressions copings prior to making the impression. Resin cement was applied to the $0.5-\mathrm{mm}$ gaps between impression copings and the solid bar. The cement was left for 15 minutes before making the impressions to avoid the peak of the chemical reaction of the resin ${ }^{(12)}$.

Poly vinyl siloxane impression material (Elite HD+, Zhermack S.P.A, Italy) was used for all transfer procedures. Putty material was hand mixed while light material was mixed using hand dispenser that injected around the analogue. Impression copings were hand tightened with guide pins onto the analogue and then all impressions were made.

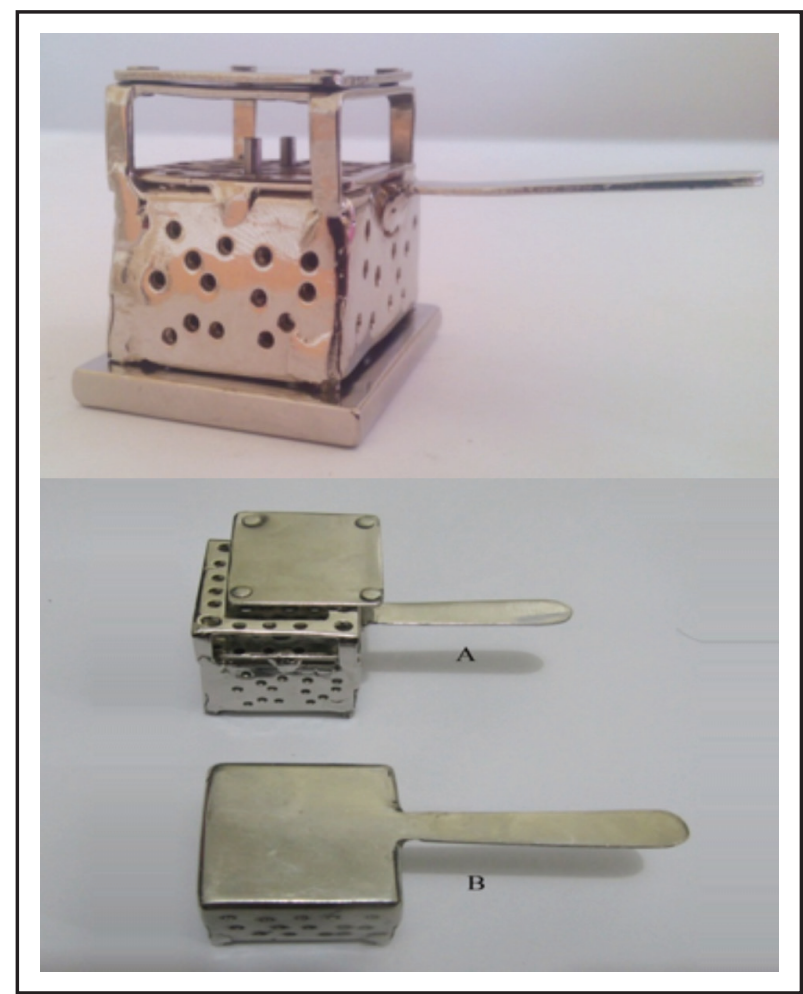

Fig. (2): A photograph showing both closed and open tray (A) open tray, (B) closed tray and long screws passing through open tray holes

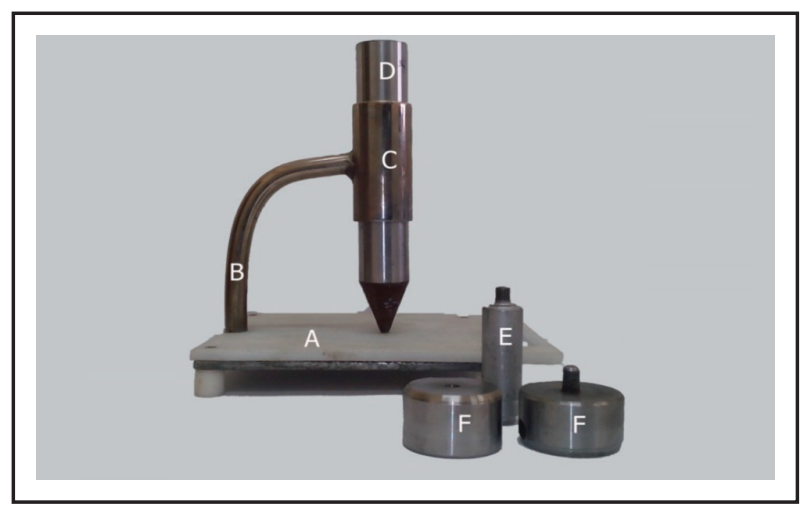

Fig. (3): A photograph showing load applicator device, (A) the base, (B) curved arm, (C) metallic ring, (D) the main bar, (E) the additional bar, (F) auxiliary loads.

The custom trays were seated using load applicator. The same dentist manually attached the analogues to the copings. All impressions were poured using vacuum mixer and type IV dental stone.

All casts obtained of the three different techniques are kept for one day before measuring. Analysis was 
done using stereo microscope at a magnification of $8 \mathrm{X}$ and accuracy level of $0.001 \mathrm{~mm}(1 \mu)$. Accuracy was assessed by measuring inter analogue distance and considering each analogue as a fixed reference to the other analogue ${ }^{(22)}$.

\section{RESULTS}

Results are represented by mean and standard deviation (SD). The significance level was set to $\mathrm{P}$ $\leq 0.05$ while no significance difference when $\mathrm{P}>$ 0.05 . All results are represented in table (1), figure (4). There was no statistically significant difference between both splinted and no splinted open tray technique with the master and within each other mold while there was significant difference with closed tray technique with the master mold and the other two techniques. $(\mathrm{p}>0.05)$

Table (1): Comparison between the three groups within each other and within the master mold.

\begin{tabular}{|c|c|c|l|}
\hline $\begin{array}{c}\text { Master } \\
\text { mold }\end{array}$ & Group & SD & P-value \\
\hline \multirow{3}{*}{11.27} & $\begin{array}{c}\text { Open splinted } \\
(\text { OS })\end{array}$ & $0.11007^{\mathrm{a}}$ & 0.141 \\
\cline { 2 - 4 } & $\begin{array}{c}\text { Closed } \\
(\mathrm{C})\end{array}$ & $0.27597^{\mathrm{b}, *}$ & 3.141 \\
\cline { 2 - 4 } & $\begin{array}{c}\text { Open } \\
(\mathrm{O})\end{array}$ & $0.09871^{\mathrm{a}}$ & 0.097 \\
\hline
\end{tabular}

Non-significant from each other

Significant with other groups

*significant with the master mold

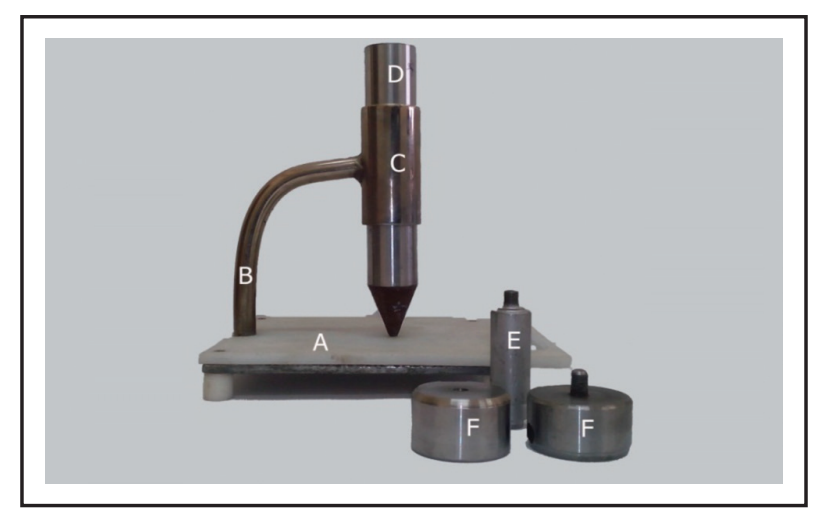

Figure (4): Diagrammatic chart showing accuracy difference between the three techniques and the master mold.

\section{DISCUSSION}

When dealing with implant supported prosthesis, reducing stresses upon implant-bone system is mandatory for survival and success of implant and superstructure by achieving passivity as possible. The natural tooth moves about $100 \mu$ within the socket while implant has a range of $10 \mu$ so any misfit will lead to destructive complications within implant, bone and superstructure ${ }^{(8)}$.

Two standardized stainless steel trays were made. One for closed technique, while the other for open tray technique. For both trays, the upper side of the tray was $8 \mathrm{~mm}$ away from the mold allowing for $5 \mathrm{~mm}$ for length of the analogue and $3 \mathrm{~mm}$ as a thickness for impression material ${ }^{(15)}$. The design of the tray was coinsize with Cho et al that revealed the used of rigid metal stock trays is preferred than custom trays. For complete standardization of impression procedures, a fixed load corresponding to finger pressure was the method for seating all impressions avoiding variations of operator pressure till setting of impression material ${ }^{(15,24)}$.

Poly vinyl siloxane (PVS) was the material of choice in this study due to appropriate resiliency and its improved accuracy. Polymerization shrinkage due to rearrangement of the polymer chains and the cross-linking are causative factors to deformation. PVS was preferred in most clinical situation in comparison to poly ether impression material. Recent studies stated that PVS is the suitable material as impression material for multiple implants when comparing with other materials. One step technique was used for making all impressions of the three techniques to allow for uniform distribution of the light material and avoid manual relief of the putty material in putty/wash technique that was agreed by many researchers whom compared between the two techniques as other studies affirms the use of one step technique rather than a putty/wash technique ${ }^{(17,18)}$. 
Many materials were used for splinting as acrylic resin with its different types dual cured and auto polymerizing, plaster impression material, poly vinyl siloxane and poly ether impression material, composite resin and resin cement. All these materials showed a degree of shrinkage that may affect accuracy of transfer. The popular method of splinting material is acrylic resin shows volumetric shrinkage of $6.5 \%$ to $7.9 \%{ }^{(16)}$.

The technique used for making splint in this study was based on that of Brian Myung et al , in which a solid bar splint was lathe cut to avoid the drawbacks of other materials as it is a stable material and no deformation / time occurs. Since 1986, several implant transfer techniques were introduced. The impression techniques used in this study were closed technique and open techniques. Open technique allows the transfers to be splinted which doesn't occur in the closed tray technique since the transfer remains fixed to the implant after the impression is removed ${ }^{(4)}$.

The first group of this study was closed tray technique. The closed tray technique is characterized by simplicity, no special equipments needed, suitable for gaggers and time saving, however it shows more deformation and rotational discrepancy increases when the screws are repositioned to connect implant analogue to impression copings. The second group was no splinted open tray technique. This technique is characterized by that no need for repositioning the transfer copings, implant angulations, and the transfer copings do not deform the impression material upon removal. Although increased chance of accuracy within this technique, it is complicated and sensitive that may be annoying for many patients. The third group was splinted open tray technique. It is a modification of open tray technique. The coping splinting is done to transfer the relationship of implants accurately to the master model, providing higher stability within impression material. The splint material used in this study was metallic splint that cemented to the coping using resin cement.
The result of this study showed that there was a statistically significant difference between closed tray technique and the master mold while there was no significant difference between both no splinted, splinted pick up techniques and the master mold.

In 2015, A study transacted a systematic review to classify the implant impression studies by techniques used and to understand the characteristics of each method. A total of 56 studies met the inclusion criteria for this review. Within the results of this systematic review, the researchers concluded that within the recent publications open tray technique showed more accurate results than the indirect one, while direct splinted technique showed more accurate results than direct non splinted one ${ }^{(19)}$.

In this study, closed tray showed significant deviation than the master mold that may be related to many factors. The main and problematic factor is manual transfer and fastening of the coping that distort coping positioning during both coping removal and reinsertion, stresses generated upon the coping and the impression material upon removal that induce distortion in addition to length of the coping occupied within the impression material as short coping is usually used with closed technique. Other factors were related to shrinkage of impression material, dental stone, screwing torque and coping deviation upon force effect generated due to tray positioning and removing. Regarding other techniques, the study revealed that there was no significant difference affecting the accuracy in comparison with the master mold.

These results concerning closed and open tray coincided with previous studies that revealed open tray techniques are more accurate than closed tray technique. Many studies concluded the same results when comparing three different impression techniques while few studies conflict our results ${ }^{(21,23)}$. Another study disagreed the results of this study when comparing different impression techniques with different impression materials and finally revealed that there was no significant difference between open and closed impression techniques and affirmed that both techniques exerts 
the same distortion within the final cast. This result was explained by in the open tray due to the rotation of the impression coping with a long screw in the material when unscrewing and removing the impression from the model or while screwing the analogue into the impression coping that occurs mostly counterclockwise which may indicate rotation of copings during unscrewing the screw from top of the tray ${ }^{(20)}$.

Concerning splinting effect, this study showed no significant effect of splinting of transfer coping that coincide with many researches as proved by many studies ${ }^{(16,19,25,26)}$. while another study argued these results by comparing effect of splinting upon the accuracy of impression techniques and concluded impression techniques with splinted transfers promoted better accuracy than non-splinted one, regardless of the splinting material utilized that explained by better distribution of stresses upon the transfers upon seating and removal also splinting keep fixed relation between the different transfers within unscrewing/transfer step ${ }^{(23)}$.

It is difficult to compare clinical application with this in vitro investigation that eliminated the multiple factors of the oral cavity environment including mouth opening limitation, arch flexure, angulation of implants and teeth in relation to each other, effect of finger pressure, tray insertion and removal, effect of surrounding structure, type of the coping used and finally clinician experience. Finally, future researches could replicate this study and evaluate the effects of these factors with each other. Also in vivo studies will give better recommendation than vitro studies.

\section{CONCLUSION}

\section{Within the limitation of this study:}

1. Open tray techniques are preferred than closed tray technique for implant impression.

2. No -splinted open tray technique is preferred as it is less complicated.

\section{REFERENCES}

1. Tabe M, Alikhasi M, Siadat A. A Comparison of implant impression precision: Different materials and techniques Int J Dent Res. 2018; 5: 22-32.

2. Elshenawy E, Alam-Eldein A, Abd Elfatah F. Cast accuracy obtained from different impression techniques at different implant angulations (in vitro study). Int $\mathbf{J}$ Implant Dent. 2018; 4: 9.

3. Selvara S, Dorairaj J, Mohan J, Simon P. Comparison of implant cast accuracy of multiple implant impression technique with different splinting materials: An in vitro study. J Ind Prosth Soc. 2016; 16: 167-75.

4. Saboury A, Asli H, Kajan Z. The Accuracy of Four Impression-making Techniques in Angulated Implants Based on Vertical Gap. Int J Dent (Shiraz). 2017; 18: 289 - 97.

5. Haghi H, Shiehzadeh M, Nakhaei M, Ahrary F, Sabzevari $\mathrm{S}$. Effect of technique and impression material on the vertical misfit of a screw-retained, three-unit implant bridge: An in vitro study J Ind Prosth Soc. 2017; 17: 41-7.

6. Gupta S, Narayan A, Balakrishnan D. In Vitro Comparative Evaluation of Different Types of Impression Trays and Impression Materials on the Accuracy of Open Tray Implant Impressions: A Pilot Study. Int Dent J. 2017; $17: 44-56$.

7. Patil R, Kadam P, Oswal C, Patil S, Jajoo S, Gachake A. A comparative analysis of the accuracy of implant master casts fabricated from two different transfer impression techniques. Int J Soc Prev Community Dent. 2016; 6: 142- 8 .

8. Tamer $\mathrm{O}$ and Wael G. Composite resin versus two different splinting techniques on evaluation of impression accuracy for dental implants. Life Science 2013; 10:1013-8.

9. Anilsharma, Anuj C, Neeraj M, Natasha M. Contemporary impression techniques in implant prosthontics. Ind J Dent. 2010; 2:61- 4 .

10. S Bhakta, Vere J, Calder I, Patel R. Impressions in Implant dentistry. Br Dent J 2011; 211:361-7.

11. Cho GC and Chee WW. Distortion of disposable plastic stock trays when used with putty vinyl polysiloxane impression materials. J Prosth Dent.2004; 92: 354-8.

12. Sorrentino R, Gherlone EF, Calesini G, Zarone F. Effect of implant angulation, connection length, and impression material on the dimensional accuracy of implant 
impressions: an in vitro comparative study. Clin Implant Dent. 2009; 10:2-14.

13. Khaled Al, Roya Z, Matthew F, Hiroshi H. An in vitro comparison of the accuracy of implant impressions with coded healing abutments and different implant angulations. J Prosth Dent. 2013; 110:90-100.

14. Herbst D, Nel JC, Driessen CH, Becker PJ. Evaluation of impression accuracy for Osseo integrated implant supported superstructures. J Prosth Dent. 2000; 83:555-61.

15. Papaspyridakos P, Benic GI, Hogsett VL, White GS, Lal K, Gallucci GO. Accuracy of implant casts generated with splinted and non-splinted impression techniques for edentulous patients: An optical scanning study. Clin Oral Implants. 2012; 23:676-81.

16. Marzieh A, Seyed Hossein B, Roshanak N. Effect of Multiple Use of Impression Copings on the Accuracy of Implant Transfer. Int J O Max Imp. 2013; 28:408-14.

17. Jung H, Chang-Whe K, Young-Jun L. Comparative accuracy of the splinted and un splinted impression methods for internal connection. K J Prosth. 2005; 3:43-50.

18. Donovan TE and Chee WW. A review of contemporary impression materials and techniques. Dent Clin North Am. 2004; 48: 445-70.
19. Del'acqua MA, De Avila ÉD, Amaral ÂL, Pinelli LA Comparison of the accuracy of plastic and metal stock trays for implant impressions. Int J O Max Imp. 2012; 27: 544-50.

20. Jee-Hwan Kim, A Kyoung Rok Kim, Sunjai Kim. Critical appraisal of implant impression accuracies: A systematic review. Int J Prosth Dent. 2015; 114:185-95.

21. Behnaz E, Mansor R, Badrosadat D, Farshad B. Effect of different impression materials and techniques on the dimensional accuracy of implant definitive casts. Dent Res J. 2015; 12:136-43.

22. Stimmelmayr M, Güth JF, Erdelt K, Happe A, Schlee M, Beuer F. Clinical study evaluating the discrepancy of two different impression techniques of four implants in an edentulous jaw. Clin Oral Invest. 2013; 17:1929-35.

23. Lee YJ, Heo SJ, Koak JY, Kim SK. Accuracy of different impression techniques for internal-connection implants. Int J O Max Imp. 2009; 24:823-30.

24. Humberto G, Quinelli M, Eduardo V. Accuracy of Impression Techniques for Implants. Part 2 - Comparison of Splinting Techniques. Int J Prosth. 2009; 18: 172-6.

25. Alikhasi M, Bassir S, Naini R. Effect of multiple use of impression copingss on the accuracy of implant transfer. Int J O Max Imp. 2013; 28:408-14. 